\title{
Effects of the inoculation of cyanobacteria on the microstructure and the structural stability of a tropical soil
}

Oumarou Malam Issa ${ }^{1}$, Christian Défarge ${ }^{2}$, Yves Le Bissonnais ${ }^{3}$, Béatrice Marin ${ }^{1}$, Odile Duval $^{4}$, Ary Bruand ${ }^{2}$, Luigi Paolo D'Acqui ${ }^{5}$, Sofie Nordenberg ${ }^{2}$ and Marcus Annerman ${ }^{4}$

(1) Université de Reims Champagne-Ardenne, GEGENA EA 3795, CREA 2 Esplanade Roland Garros, 51100 Reims, France

(2) Institut des Sciences de la Terre d'Orléans, U.M.R. 6113 C.N.R.S.-Université d'Orléans, 45067 Orleans cedex 2, France

(3) INRA LISAH (Laboratoire d'étude des Interactions Sol- Agrosystème-Hydrosystème), Unité Mixte de Recherche ENSA.M INRA-IRD Campus AGRO, Bat. 24-2 place Viala, 34060 MONTPELLIER Cedex 1, France

(4) INRA, Unité de Science du Sol, Centre de Recherche d'Orléans, Avenue de la Pomme de Pin, 45160 Ardon, France

(5) Istituto per lo Studio degli Ecosistemi ISE-CNR, Via Madonna del Piano, 50019 Sesto

Fiorentino, Italy

Oumarou Malam Issa

Email: Oumarou.Malam-Issa@univ-reims.fr

Fax: $+33-326-773694$

\begin{abstract}
Cyanobacteria are widespread photosynthetic microorganisms among which some are able to fix atmospheric nitrogen. We investigated the impact of indigenous cyanobacteria strains (Nostoc) inoculation on physical characteristics of poorly aggregated soils from Guquka (Eastern Cape, South Africa). The soil aggregates $(3-5 \mathrm{~mm})$ were arranged into a layer of 10 $20 \mathrm{~mm}$ thick, and sprayed with cyanobacteria solution. Subsequently the inoculated and uninoculated samples were incubated $\left(30^{\circ} \mathrm{C}, 80 \%\right.$ humidity, continuous illumination at $\left.100 \mu \mathrm{mol} \mathrm{m} \mathrm{s}^{-1}\right)$. Their micromorphological characteristics and aggregate stability were investigated, after 1, 2, 3, 4 and 6 weeks of incubation, by using high resolution Cryo-SEM and aggregate breakdown tests.

Micromorphological investigations revealed that the surface of un-inoculated samples remained uncovered, while the inoculated samples were partially covered by cyanobacteria material after one week of incubation. A dense superficial network of cyanobacterial filaments and extracellular polymer secretions (EPS) covered their surface after 4 and 6 weeks of incubation. Organo-mineral aggregates comprising cyanobacterial filaments and EPS were observed after 6 weeks of incubation. The results of aggregate breakdown tests showed no significant difference between un-inoculated samples after 1, 2, 3, 4 or 6 weeks, while they revealed improvement of aggregate stability for inoculated samples. The improvement of aggregate stability appeared in a short while following inoculation and increased gradually with time and cyanobacteria growth. The increase in aggregate stability is likely related to the changes induced in micromorphological characteristics by cyanobacterial filaments and EPS. It reflects the effect of coating, enmeshment, binding and gluing of aggregates and isolated mineral particles by cyanobacteria material.
\end{abstract}


Our study presents new data demonstrating the improvement of soil physical quality in a few weeks after cyanobacteria inoculation. The interaction of the inocula and other biotic components is worthy of study before field application of cyanobacteria.

Keywords : Cryo-SEM - Cyanobacteria - Inoculation - Nostoc - Organo-mineral aggregates - Structural stability

\section{Introduction}

Cyanobacteria are colonising microorganisms that are found throughout the world, in marine, freshwater and terrestrial environments. These organisms are remarkably well adapted to a wide range of environmental conditions. They are photosynthesizers and some of them are able to fix atmospheric nitrogen. Their cells are generally surrounded by a polysaccharide sheath or capsule able to hold water and to confer to cyanobacteria a great tolerance to desiccation (Whitton 1987). Their pigment equipment allows them to withstand high levels of ultraviolet irradiation (Campbell 1979; Whitton 1992). In arid environments they form the major component of microbiotic soil crusts, i.e., microbial communities including algae, lichens and bacteria that form centimetre-thick crusts at the surface of soil (Malam Issa et al. 1999).

The beneficial effects of cyanobacteria on soil physical properties in arid environments have been demonstrated through the study of microbiotic crusts (Isichei 1990; Pérez 1997; Williams et al. 1999; Malam Issa et al. 1999 and 2001a). The most abundant microbial constituents of microbiotic crusts are filamentous cyanobacteria that exert a mechanical effect on soil particles as they form a gluing mesh and bind soil particles on the surface of their polysaccharidic sheath material (Belnap 1993; Malam Issa et al. 1999; 2001a). Cyanobacteria also excrete extracellular polymeric secretions (EPS) mainly composed of polysaccharides (Decho 1990; Hu et al. 2003). Extracellular polymeric secretions ensure the role of binding agent of soil particles (Lynch and Bragg 1985). Microbiotic crusts thus lead to the formation of tough and entangled superficial structures that improve the stability of soil surface and protect it from erosion (Malam Issa et al. 1999 and 2001a). Cyanobacterial sheaths and EPS also play a significant role in water storage due to the hygroscopic properties of polysaccharides (Decho 1990). They contribute to increased water retention capacity of soil (Verrecchia et al. 1995; Défarge et al. 1999). It has also been reported that cyanobacteria, as C and $\mathrm{N}$ fixers, can improve the nutrient content of soil in arid environments (Mayland and McIntosh 1966; Jeffries et al. 1992; Lange et al. 1994). As photosynthetic organisms they are the main primary producers, enriching the soil with organic matter and favouring biological activity (Lange et al. 1994). They also represent a potential source of nitrogen, which may be beneficial for forthcoming crop production (Rogers and Burns 1994; Zaady et al. 1998; Malam Issa et al. 2001b).

Given their beneficial effects on soil, cyanobacteria have been used as inoculants in attempts to improve soil structure, increase soil fertility or recover damaged soil crusts (Rao and Burns 1990a, b; Rogers and Burns 1994; Falchini et al. 1995; Zulpa de Caire et al. 1997; Ghosh and Saha 1997; Buttars et al. 1998; Fernandez Valiente et al. 2000; Acea et al. 2001; Hu et al. 2002, 2003; Pandey et al. 2005). Applied in rice or oil-seed rape cultivation cyanobacteria supplied soil with nutrient and significantly increased productivity (Watanabe and Yamamoto 1971; Stewart et al. 1979; Reynaud 1987; Rao and Burns 1990a, b; Ghosh and Saha 1997; Fernandez Valiente et al. 2000). The results obtained by Roger and Burns (1994) indicated 
significant increase of seedling emergence in soils inoculated with Nostoc muscorum compared to the un-inoculated soils. When used for recovering disturbance due to trampling, ploughing and wildfire, cyanobacteria promoted establishment of microbial population, increased organic matter and nutrient content and also soil stability (Ashley and Rushforth 1984; St. Clair et al. 1986; Johansen et al. 1994; Buttars et al. 1994, 1998; Acea et al. 2001, 2003).

Although many works have dealt with the use of cyanobacteria inoculation as soil conditioners, work on the short- and long-term changes following inoculation is needed. The work presented here is the first step of an EU project (Cyanosoils) on the use of local strains of cyanobacteria to improve resilience and overall soil fertility in arid soils. The work is based on laboratory experiments and comparison between micromorphological characteristics and aggregate stability of inoculated and un-inoculated soil samples. It aims to improve our knowledge about the changes in soil microstructure and physical properties during the early stage following cyanobacteria inoculation into soil.

\section{Materials and methods}

The soil was collected from a site located in the Eastern Cape Province (South Africa) near the village of Guquka (32 $\left.39^{\prime} \mathrm{S}, 26^{\circ} 57^{\prime} \mathrm{E}\right)$, a rural settlement of about 130 households with arable and grazing lands.

Major textural characteristics of the soil are shown in Table 1. It is a cultivated ferruginous tropical soil classified as a Typic Plinthustalf (Soil taxonomy) and as a Ferric Luvisol soil in the FAO system (FAO 1994). The soil was chosen because of its low physical and chemical fertility, resulting from its inherently low organic content and its particle size (Table 1 ). The soil samples have a sandy clay loam texture, an acidic $\mathrm{pH}$ value and low total organic carbon (TOC) and nitrogen contents (Table 1). Values of mean weight diameter (MWD) ranged from 0.4 to $0.8 \mathrm{~mm}$, which are characteristic of unstable soil sensitive to crust formation and sealing after rain (Bresson and Valentin 1994; Le Bissonnais 1996). After sampling, soil aggregates were air-dried and sieved between $3-5 \mathrm{~mm}$, then stored in a cold room until they were inoculated with cyanobacteria.

The experiments of inoculation were performed using a strain of cyanobacterium belonging to the genus Nostoc. This strain was isolated from a tropical soil from Tanzania, another site studied during the Cyanosoils project. It was selected because it showed a high growth rate both on culture medium and on soil, but also due to its ability to produce EPS and to fix nitrogen.

Soils aggregates were arranged in a layer of $1 \mathrm{~cm}$ thick in a plastic ring of $14 \mathrm{~cm}$ in diameter and $4 \mathrm{~cm}$ in height. One set of samples was inoculated by spraying their surface with a cyanobacteria solution containing $3 \mathrm{~g} \mathrm{l}^{-1}$ of inoculum. Duplicate inoculated and un-inoculated samples were placed in an incubator where the temperature was maintained at $30^{\circ} \mathrm{C}$, the relative humidity at $80 \%$ and the illumination at $100 \mu \mathrm{mol} \mathrm{m}^{-2} \mathrm{~s}^{-1}$. The samples were maintained wet by regular spraying with deionised water and medium culture (BG 110). Both inoculated and un-inoculated samples were maintained in the incubator for $1,3,4$, and 6 weeks. When incubation was complete, samples were first air-dried, and thereafter material from the upper $5 \mathrm{~mm}$ collected. Microscopic investigations of soil structure and aggregate stability measurements were simultaneously run for inoculated and un-inoculated samples. 
The micromorphological characteristics of the selected samples were investigated with high resolution scanning electron microscope (Hitachi S-4200) equipped with a field emission gun and a dedicated cryopreparation system (Polaron LT 7400). The field emission gun allowed us to observe dry pieces of soil samples at low accelerating voltage $(1 \mathrm{kV})$ without using any coating. The cryo-system was used to observe wet samples in a state close to field conditions. This technique offers the ability to visualise the natural surface of the living components of the inoculated samples (Défarge et al. 1999).

Stability measurements were performed in triplicate according to the method of Le Bissonnais (1996) using aggregates of 3-5 $\mathrm{mm}$ in size, obtained by sieving inoculated and un-inoculated samples. The method determines stability of aggregates by using a combination of three treatments, each corresponding to different wetting conditions and energy inputs: (i) the fast wetting was used to test the behaviour of dry soil samples subjected to rapid wetting events during spring or summer heavy rain storms; (ii) the slow wetting treatment, to test the behaviour of samples that are dry or with a low water content submitted to moderate rains. This test is less destructive than the rapid wetting and allows discrimination of very unstable soils; (iii) the wet stirring treatment tests the cohesion of the moist material independently of slaking. It was performed using a non-polar liquid miscible with water (ethanol) to avoid aggregates breakdown by slaking. A detailed description of the method is given by Le Bissonnais (1996), Attou et al. (1998) and Malam Issa et al. (2001a). After each treatment the particle size distribution of the resulting material was determined by a combination of wetand dry-sieving. Aggregate stability was expressed by the resulting fragment size distribution in seven granulometric classes and by the value of the MWD calculated by the following formula:

$$
M W D=\frac{\sum_{1}^{7} \overline{x_{i}} w_{i}}{100}
$$

with $\chi i$ being the mean intersieve size and $w_{i}$ the percentage of particles left on each sieve.

Multiple comparison tests (Tuckey's HSD) were used to test for significant differences in MWD values obtained for inoculated and un-inoculated samples after all treatments.

\section{Results}

\section{Surface observations}

The surface of un-inoculated samples comprised only mineral soil particles (Fig. 1A), whereas the inoculated samples comprised also Nostoc filaments and EPS produced by these cyanobacteria (Figs. 1B, 2-4). Comparison between inoculated samples incubated for 1, 4 and 6 weeks showed increase of the abundance of cyanobacteria material accompanied by gradual changes in micromorphological features. A partial cyanobacterial material cover or biofilm (composed of filaments and EPS) formed at the surface of samples inoculated for one week (Fig. 2A). The EPS material formed a discontinuous coating on the surface of isolated mineral particles (Fig. 2A). In some places EPS formed organic bridges linking together contiguous soil particles (Fig. 2). Samples inoculated for 4 and 6 weeks exhibited a densely-covered surface, resulting from the high development of cyanobacteria and the abundance of secreted 
material (Figs. 3 and 4). Cyanobacterial filaments and secreted material were closely associated and formed an intricate network (Fig. 3). They covered almost the entire surface of soil (Fig. 3A), tightly binding aggregates and particles (Figs. 3 and 4). The surface of samples inoculated for 6 weeks exhibited also organo-mineral aggregates, $150-350 \mu \mathrm{m}$ in diameter, comprising filaments and EPS (Fig. 4B).

\section{Aggregate stability}

\section{Fragment size distribution}

Figure 5 shows the fragment size distribution of material collected after the three tests of aggregate stability performed on un-inoculated and inoculated samples. The percentages of fragments larger than $2 \mathrm{~mm}$ (coarse fragments) and fragments smaller than $0.5 \mathrm{~mm}$ (fine fragments) in collected material reflected the resistance of soil samples against aggregate breakdown.

In Fig. 5A we present the fragment size distribution of material collected from un-inoculated samples. All the samples showed low resistance to aggregate breakdown, because the collected material comprised more fine fragments $(58-88 \%)$ than coarse fragments $(3-31 \%)$. Material collected after wet stirring contained $3-10 \%$ of coarse fragments and $82-88 \%$ of fine fragments. This test induced higher aggregate breakdown than the fast and slow wettings, that produced more coarse fragments (16-30\%) and less fine fragment (58-79\%).

In Fig. 5B we present the fragments size distribution of material collected after testing inoculated samples. Inoculated samples incubated for 2-6 weeks are more resistant than uninoculated samples as they produced more coarse fragments and less fine fragments. The lowest resistance to stability tests was obtained with inoculated samples incubated for 2 weeks; the percentages of $>2 \mathrm{~mm}$ and $<0.5 \mathrm{~mm}$ fragments are $3-38 \%$ and $52-86 \%$ respectively. The greatest resistance is shown by inoculated samples incubated for 6 weeks, as the materials collected after their treatments contained $17-47 \%$ of fragments smaller than $0.5 \mathrm{~mm}$ and $48-78 \%$ of fragments larger than $2 \mathrm{~mm}$. Samples inoculated for one week showed the same behaviour as the bulk of un-inoculated samples; 78-94\% of the collected material after all treatments occurred within $<0.5 \mathrm{~mm}$ size range (Fig. $\underline{5} \mathrm{~B}$ ).

Regardless the time of incubation, the highest disaggregation was obtained with the wet stirring test of stability. This test produced relatively low amount of coarse fragments (3$48 \%)$ and high amount of fine fragments (47-88\%) compare to fast and slow wettings (29$78 \%$ of coarse fragments, $17-66 \%$ of fine fragments). Samples inoculated for 4 and 6 weeks showed a significant resistance to the wet stirring, the most destructive test. The material collected after wet stirring test contained $12-48 \%$ of coarse fragments on these samples compared with $1-4 \%$ in material collected from samples inoculated for 1, 2 and 3 weeks.

\section{Mean weight diameter}


Figure 6 shows the mean weight diameter of collected particles after the three tests of aggregate stability performed on un-inoculated and inoculated samples. These results are consistent with those indicated by fragment size distributions. MWD of the un-inoculated samples ranged between $0.72-0.90 \mathrm{~mm}, 0.77-1.29 \mathrm{~mm}$ and $0.28-0.52 \mathrm{~mm}$, respectively, after fast-, slow-wetting and wet stirring (Fig. 6A). The highest value was recorded for the 6-weeks incubated samples after slow wetting. Values obtained after the fast wetting treatments were not significantly different according to the multiple comparison test (95\% Tukey's HSD). The mean value of the three tests showed no significant increase of aggregate stability between the different stages of incubation. Mean weight diameter values for inoculated samples, except those incubated for one-week, ranged between 1.14-2.34 mm, 1.25-2.81 mm and 0.31$1.77 \mathrm{~mm}$, respectively after fast-, slow-wetting and wet stirring (Fig. 6B). These values revealed a significant increase in aggregate stability after two weeks of cyanobacterial growth for fast and slow wetting tests and after four weeks of incubation for wet stirring test (Fig. 6B). There was a significant difference in MWD between inoculated and un-inoculated samples for both the fast and slow wetting tests. For the wet stirring tests only MWD of 4 and 6-weeks inoculated samples were significantly different from those of un-inoculated samples $(P=0.05)$.

\section{Discussion}

Results of stability measurements reported here showed that the strain of Nostoc inoculated into soil increases the resistance of soil aggregates to breakdown. The rate of aggregate stability increase was higher than those reported in the literature. In a similar experience Bailey et al. (1973) obtained an increase of water stability of aggregates by $14 \%$ after 6 weeks following inoculation. Rogers and Burns (1994) and Zulpa de Caire et al. (1997) reported an increase in aggregate stability of respectively $18 \%$ in average after 300 days and $66 \%$ after 365 days following inoculation of Nostoc muscorum into soil. Our results indicate an increase in aggregate stability by two to four times compared to that of un-inoculated samples 6 weeks following inoculation. From the second week of inoculation a high resistance to breakdown caused by fast- and slow-wettings was recorded, and after 6 weeks aggregates proved to resist even the wet stirring, the most destructive wetting treatment that simulates the rain drop impact. The aggregate stability values obtained after 6 weeks of cyanobacterial growth were similar to those of very stable soil material using the scale of erodibility described by Le Bissonnais (1996). These values are in the same range as those obtained on microbiotic soil crusts undisturbed for 4 years (Malam Issa et al. 2001a).

The resistance of inoculated soil aggregates to breakdown is likely related to the changes induced in micromorphological characteristics by cyanobacterial filaments and EPS. Similar to what has been observed in microbiotic soil crusts (Cameron and Devaney 1970; Belnap and Gardner 1993; Défarge et al. 1999; Malam Issa et al. 1999, 2001a), micrographs of inoculated samples show how soil particles and inoculated cyanobacteria material are bound together (Figs. 2-4). From the first week following the inoculation, cyanobacteria and abundant EPS formed a discontinuous coating over the surface of isolated mineral particles and in some places an organic-bridge between contiguous soil particles (Fig. 2). However these changes were not accompanied by improvement in aggregate stability. Moreover, aggregate stability lower than that of un-inoculated samples was recorded (Fig. 6). Perhaps this is due to the fact that spraying of inocula leads to aggregate breakdown and particle dispersion, and the 
aggregation of those dispersed particles took more than one week to reappear. After 46 weeks following inoculation a densely covered surface and an intricate network of filaments resulted from further development of cyanobacteria and secretion of EPS (Figs. 3 and 4). That leads first to coating, enmeshment and then binding of soil particles and aggregates. This stage was followed by building up of soil particles into organo-mineral aggregates by 6 weeks following inoculation of cyanobacteria into soil material. These features due to the intertwining disposition of cyanobacterial filaments, their gluing effect and the coalescence of EPS were also described in microbiotic soil crusts (Marathe 1972; Campbell 1979; Malam Issa et al. 1999, 2001a). They are responsible of the resistance of inoculated sample aggregates to breakdown by fast and slow wetting. The behaviour of the 6-week inoculated samples after the wet stirring test is likely related to the presence of organo-mineral aggregates.

Our results constitute a preliminary study of soil fertility prior to inoculation of some strains of cyanobacteria. They demonstrated the growth and proliferation of the selected cyanobacteria, their ability to produce EPS, and the improvement of soil aggregate stability. Size and stability of aggregates changed shortly after inoculation, and gradually increased with time and cyanobacteria growth. About 6 weeks were required to obtain stability values similar to that of undisturbed microbiotic soil crusts. Compared to the time required for a full and natural recovery of disturbed microbiotic crusts, i.e. 2-100 years (Cole 1990; Johansen et al. 1993; Belnap 1993). Our results showed that inoculation can increase the rate of recovery of disturbed soils. As stated by Warren (2001), subsequent improvement of water infiltration could result from cyanobacteria inoculation because stable aggregate render soil surfaces less sensitive to sealing and crusting.

The ultimate objective of the work was to increase favourable substrates for seed germination and plant growth by field inoculation of cyanobacteria. However, more information is needed. For example, the influence of other microbes on soil physical characteristics should be considered, since compounds excreted as metabolites and organic matter through death and decay of inoculated cyanobacteria stimulate proliferation of algae, bacteria, fungi, and actinomycetes (Rogers and Burns 1994; Acea et al. 2001, 2003). The interaction of the inocula and other biotic components requires field study prior to any field application of cyanobacteria.

\section{Acknowledgements}

This work formed part of CYANOSOILS project funded by European Union, contract no. ICA4-CT-2001-10058. The authors gratefully acknowledge H. Gaillard, B. Renaux and A. Richard for their skilled technical assistance. 


\section{References}

Acea MJ, Diz N, Prieto-Fernandez A (2001) Microbial populations in heated soils inoculated with cyanobacteria. Biol Fertil Soils 33:118-125

Acea MJ, Prieto-Fernández A, Diz-Cid N (2003) Cyanobacterial inoculation of heated soils: effect on microorganisms of $\mathrm{C}$ and $\mathrm{N}$ cycles and on chemical composition in soil surface. Soil Biol Biochem 35:513-524

Attou F, Bruand A, Le Bissonnais Y (1998) Effect of clay content and silt-clay fabric on stability of artificial aggregates. Eur J Soil Sci 49:569-577

Ashley J, Rushforth SR (1984) Growth of soil algae on top soil and processed oil shale from the Uintah Basin Utah USA. Reclam Reveg Res 3:49-63

Bailey D, Mazurak AP, Rosowski JR (1973) Aggregation of soil particles by algae. J Phycol 9:99-101

Belnap J (1993) Recovery rates of cryptobiotic crusts: inoculant use and assessment methods. Great Basin Nat 53:89-95

Belnap J, Gardner JS (1993) Soil microstructure in soils of the Colorado Plateau: the role of the cyanobacterium Microcoleus vaginatus. Great Basin Nat 53:40-47

Bresson LM, Valentin C (1994) Soil surface crust formation: contribution of micromorphology. In Soil micromorphology: studies in management and genesis. AJ Ringrose-Voase and GS Humphreys (eds). pp. 737-762. Developments in Soil Science 22, Elsevier, Amsterdam.

Buttars SA, St. Clair LL, Johansen JR, Warren S, Pendleton B (1994) Stabilization of damaged soil crust communities using cyanobacterial amendments: greenhouse studies. Am J Bot 81(6):106

Buttars SM, St. Clair LL, Johansen JR, Sray JC, Payne MC, Webb BL, Terry RE, Pendleton BK, Warren SD (1998) Pelletized cyanobacterial soil amendments: laboratory testing for survival, escapability, and nitrogen fixation. Arid Soil Res Rehab 12:165-178

Cameron RE, Devaney JR (1970) Antarctic soil algal crusts; scanning electron and optical microscope study. Trans Amer Microsc Soc 89:264-273

Campbell SE (1979) Soil stabilization by prokaryotic desert crust: implications for precambrian land biota. Origin Life 9:335-348

Cole DN (1990) Trampling disturbance and recovery of cryptogamic soil crusts in Grand Canyon National Park. Great Basin Nat 50:321-325

Decho AW (1990) Microbial exopolymer secretions in ocean environments: their role(s) in food webs and marine processes. Oceanogr Mar Biol 28:73-153

Défarge C, Malam Issa O, Trichet J (1999) Apports du cryo-microscope électronique à balayage à émission de champ à l'étude des matières organiques et des relations organo- 
minérales naturelles II- Application aux croûtes microbiotiqes des sols. CR Acad Sci II A 328:591-597

Falchini L, Sparvoli E, Tomaselli L (1995) Effect of Nostoc (Cyanobacteria) inoculation on the structure and stability of clay soils. Biol Fertil Soils 23:346-352

FAO (1994) World reference base for soil resources. FAO, Rome, Italy, pp. 161

Fernandez Valiente E, Ucha A, Quesada A, Leganes F, Carreres R (2000) Contribution of $\mathrm{N}_{2}$ fixing cyanobacteria to rice production: availability of nitrogen from $15 \mathrm{~N}$-labelled cyanobacteria and ammonium sulphate to rice. Plant Soil 221:107-112

Gosh TK, Saha KC (1997) Effects of inoculation of cyanobacteria on nitrogen status and nutrition of rice (Oryza sativa L.) in an Entisol amended with chemical and organic sources of nitrogen. Biol Fertil Soils 24:123-128

Hu C, Liu Y, Song L, Zhang D (2002) Effect of desert soil algae on the stabilisation of fine sands. J Appl Phycol 14:281-292

Hu C, Liu Y, Paulsen BS, Petersen D, Klaveness D (2003) Extracellular carbohydrate polymers from five desert soil algae with different cohesion in the stabilisation of fine sand grain. Carbohyd Polym 54:33-42

Isichei AO (1990) The role of algae and cyanobacteria in arid lands: a review. Arid Soil Res Rehab 4:1-17

Jeffries DL, Klopatek JM, Link SO, Bolton Jr H (1992) Acetylene reduction by cryptogamic crusts from a blackbrush community as related to resaturation and dehydration. Soil Biol Biochem 24:1101-1105

Johansen JR, Ashley J, Rayburn R (1993) Effects of rangefire on soil algal crusts in semiarid shrub-steppe of the lower Columbia Basin and their subsequent recovery. Great Basin Nat $53: 73-88$

Johansen JR, Kasper K, St. Clair LL, Warren S, Pendleton B (1994) Stabilization of damaged soil crust communities using cyanobacterial amendments: development of inocula and field testing. Am J Bot 81(6): 108

Lange OL, Meyer A, Zellner H, Heber U (1994) Photosynthesis and water relations of lichen soil crusts: field measurements in the coastal fog zone of the Namib Desert. Funct Ecol $8: 253-264$

Le Bissonnais Y (1996) Aggregate stability and assessment of soil crustability and erodibility: I Theory and methodology. Eur J Soil Sci 47:425-437

Lynch JM, Bragg E (1985) Microorganisms and aggregate stability. In advances in Soil Sciences, Springer-Verlag, New York, pp. 134-170 
Malam Issa O, Trichet J, Défarge C, Couté A, Valentin C (1999) Morphology and microstructure of microbiotic soil crusts on a tiger bush sequence (Niger, Sahel). Catena 37:175-196

Malam Issa O, Le Bissonnais Y, Défarge C, Trichet J (2001a) Role of a microbial cover on structural stability of a sandy soil in Sahelian part of western Niger. Geoderma. 101:15-30

Malam Issa O, Stal JL, Défarge C, Couté A, Trichet J (2001b) Nitrogen fixation by microbial crusts from desiccated Sahelian soils (Niger). Soil Biol Biochem 33:1425-1428

Marathe K (1972) Role of some blue-green algae in soil aggregation. In: Desikachary (ed) Taxonomy and biology of Blue-Green algae. Bangalore press, India, pp 328-331

Mayland HF, McIntosh T H (1966) Availability of biologically fixed atmospheric nitrogen-15 to higher plants. Nature 209:421-422

Pandey KD, Shukla PN, Giri DD, Kashyap AK (2005) Cyanobacteria in alkaline soil and the effect of cyanobacteria inoculation with pyrite amendments on their reclamation. Biol Fert Soils 41:451-457

Pérez FL (1997) Microbiotic crusts in the high equatorial Andes, and their influence on paramo soil. Catena 31:173-198

Rao DLN, Burns RG (1990a) The effect of surface growth of blue-green algae and bryophytes on some microbiological, biochemical, and physical soil properties. Biol Fert Soils 9:239-244

Rao DLN, Burns RG (1990b) Use of blue-green algae and bryophyte biomass as a source of nitrogen for oil-seed rape. Biol Fert Soils 10:61-64

Reynaud PA (1987) Ecology of nitrogen-fixing cyanobacteria in dry tropical habitats of west Africa: a multivariate analysis. Plant Soil 98:203-220

Rogers SL, Burns RG (1994) Changes in aggregate stability, nutrient status, indigenous microbial populations and seedling emergence, following inoculation of soil with Nostoc muscorum. Biol Fert Soils 18:209-215

St Clair LL, Johansen JR, Webb B (1986) Rapid stabilization of fire-disturbed sites using a soil crusts slurry: inoculation studies. Reclam Reveg Res 4:261-269

Stewart WDP, Rowell P, Ladha JK, Sampaio MJAM (1979) Blue-green algae (cyanobacteria). Some aspects related to their role as source of fixed nitrogen in paddy soils. Plant Soil 57:137-142

Verrecchia E, Yair A, Kidron GJ, Verrecchia K (1995) Physical properties of the psammophile cryptogamic crust and their consequences to the water regime of sandy soils, north-western Negev desert, Israël. J Arid Envir 29:427-437

Warren SD (2001) Biological soil crusts and hydrology in North American deserts. In: Belnap J, Lange OL (eds) Biological soil crusts: structure, function, management. Springer, Berlin, Germany, pp 327-337 
Watanabe A, Yamamoto Y (1971) Algal nitrogen fixation in the tropics. Plant Soil special volume, 403-413

Williams JD, Dobrowolski JP, West NE (1999) Microbiotic crust influence on unsaturated hydraulic conductivity. Arid Soil Res Rehab 13:145-154

Whitton BA (1987) Survival and dormancy of blue-green algae. In: Henis Y (ed) Survival, dormancy of microorganisms. Wiley, New York, pp 109-167

Whitton BA (1992) Diversity, ecology and taxonomy of the cyanobacteria. In Mann NH, Carr NG (eds) Photosynthetic Prokaryotes. Plenum Press, New York. pp 1-51

Zaady E, Groffman P, Shachak M (1998) Nitrogen fixation in macro- and microphytic patches in the Negev Desert. Soil Biol Biochem 30:449-454

Zulpa de Caire G, Storni de Cano M, Zaccaro de Mulé MC, Palma RM, Colombo K (1997) Exopolysaccharides of Nostoc muscorum (Cyanobacteria) in the aggregation of soil particles. J Appl Phycol 9:249-253 


\section{Figures}

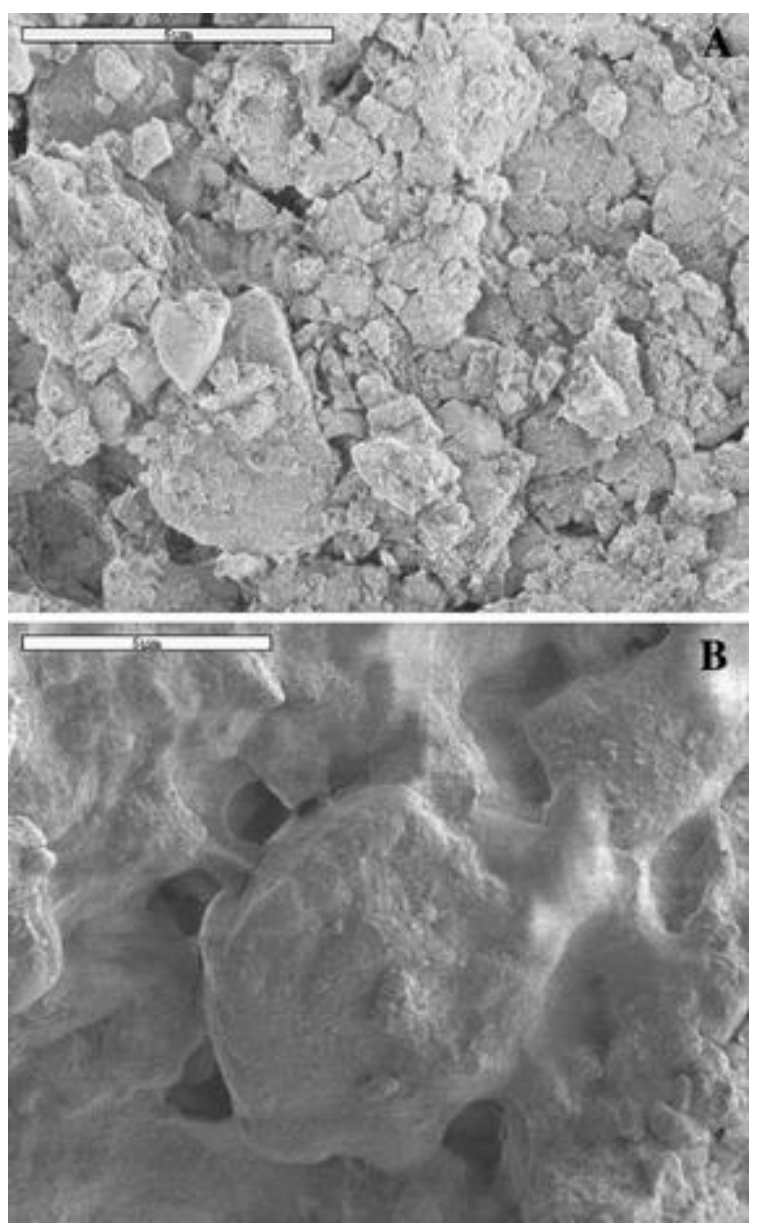

Fig. 1 SEM micrographs of the soil surface Comparison between inoculated and uninoculated samples. (A) View of the surface of un-inoculated sample. Note that only mineral particles can be observed. (B) View of the surface of an inoculated sample. It is covered by an organic film. Note the extracellular polymer secretions in the interspaces between mineral particles 


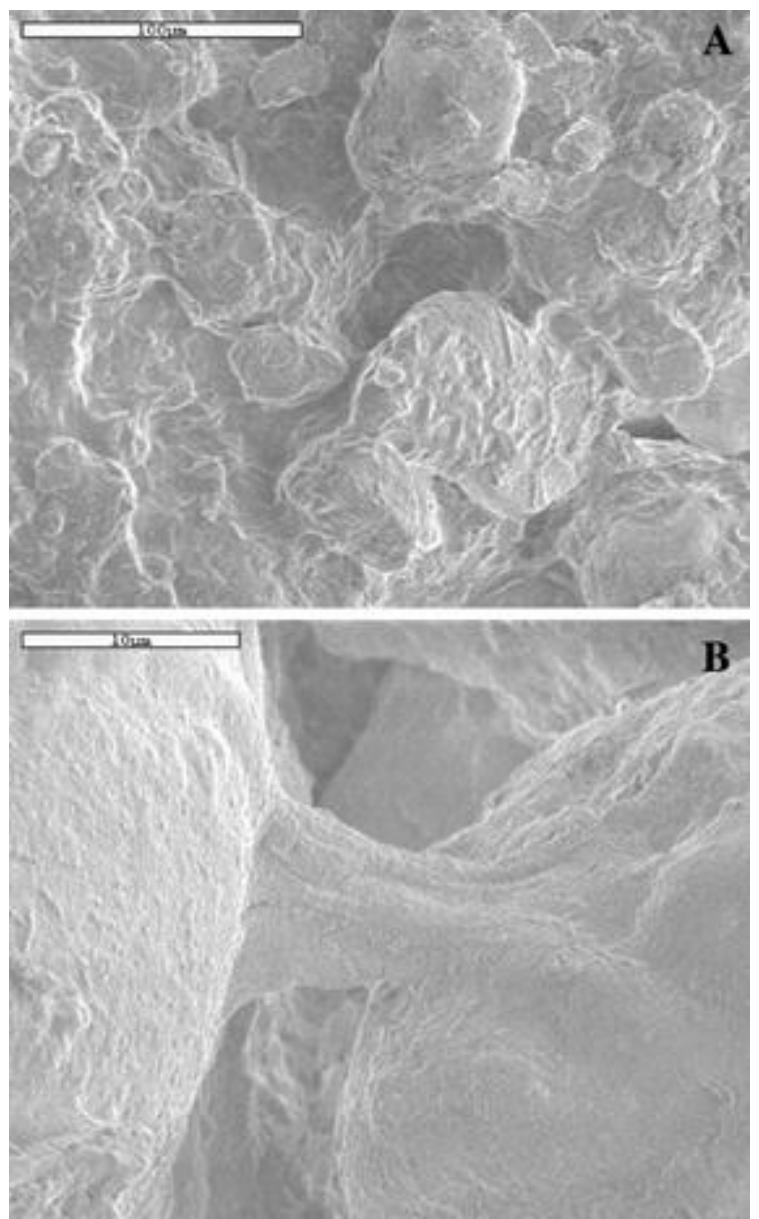

Fig. 2 SEM micrographs of the soil surface. Sample inoculated for one week. (A) General view showing a partial coating of isolated mineral particles by cyanobacterial filaments and EPS. Note the presence of organic bridges between soil mineral particles. (B) Close-up of an organic bridge between two mineral particles 

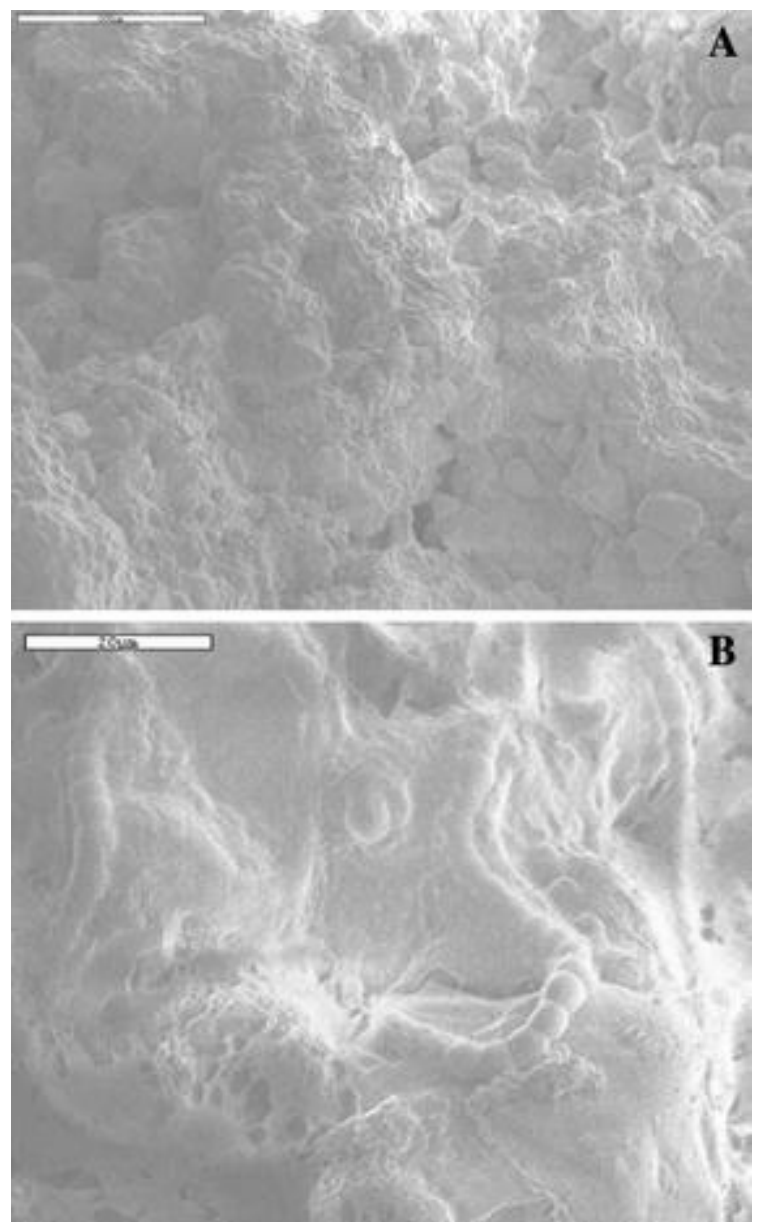

Fig. 3 SEM micrographs of the soil surface. Sample inoculated for 4 weeks. (A) General view of the surface. Note the biofilm that covers the surface and binds together soil particles. (B) Close-up of the biofilm formed of extracellular polysaccharide secretions associated with Nostoc filaments exhibiting recognizable individual cells 

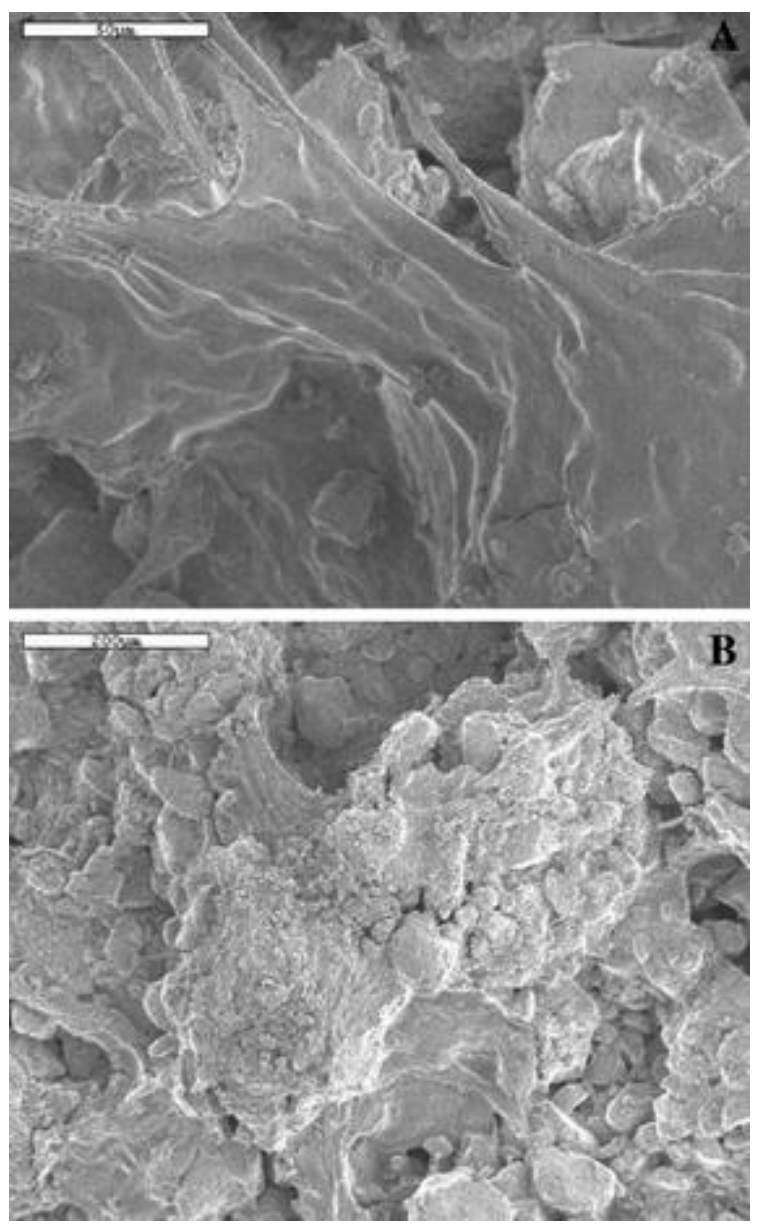

Fig. 4 SEM micrographs of the soil surface. Samples inoculated for 6 weeks. (A) View of the biofilm covering the surface of soil. (B) View of an organo-mineral aggregate of extracellular polysaccharide secretions and mineral particles 


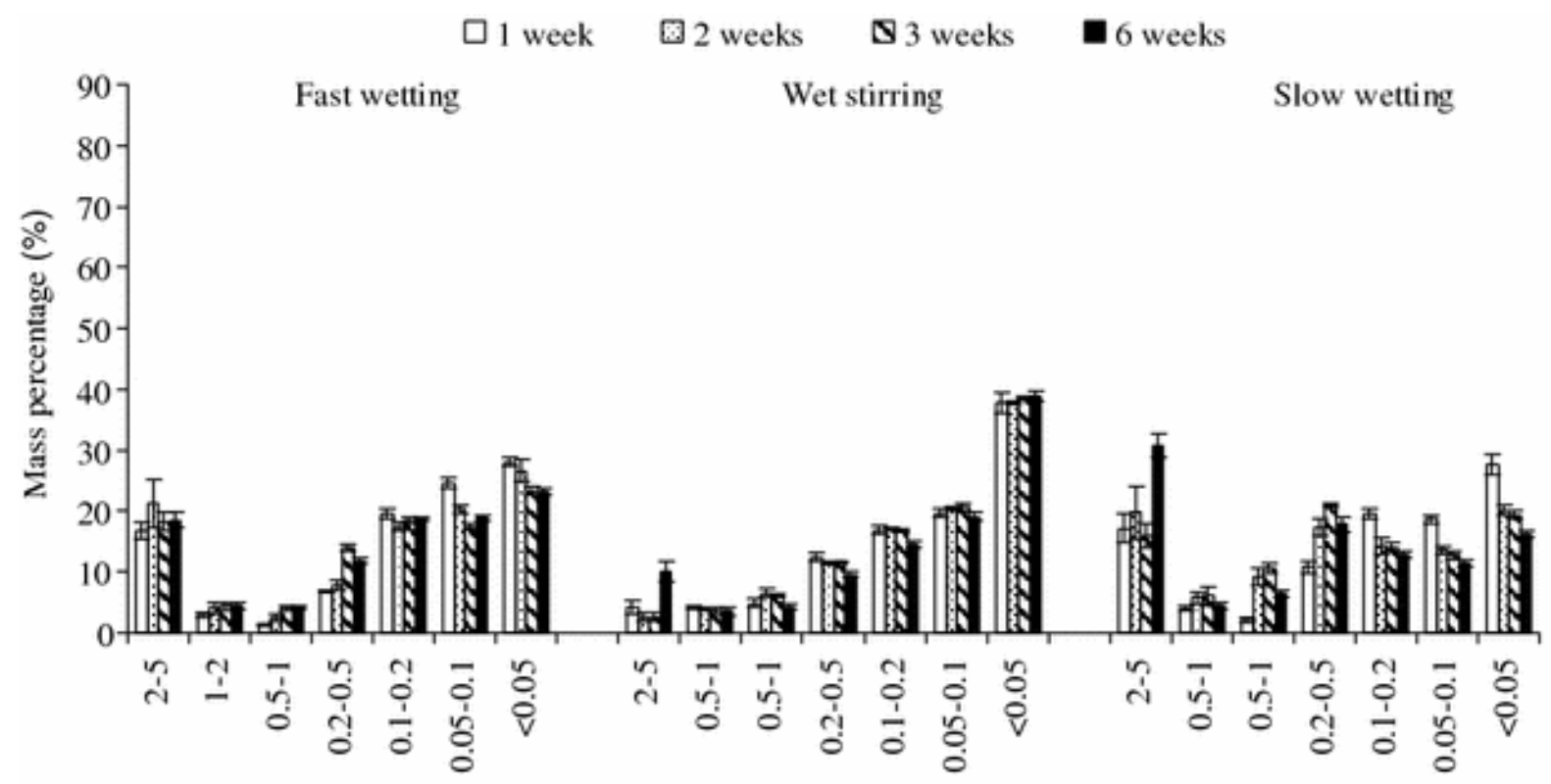

Fragment size classes (mm)

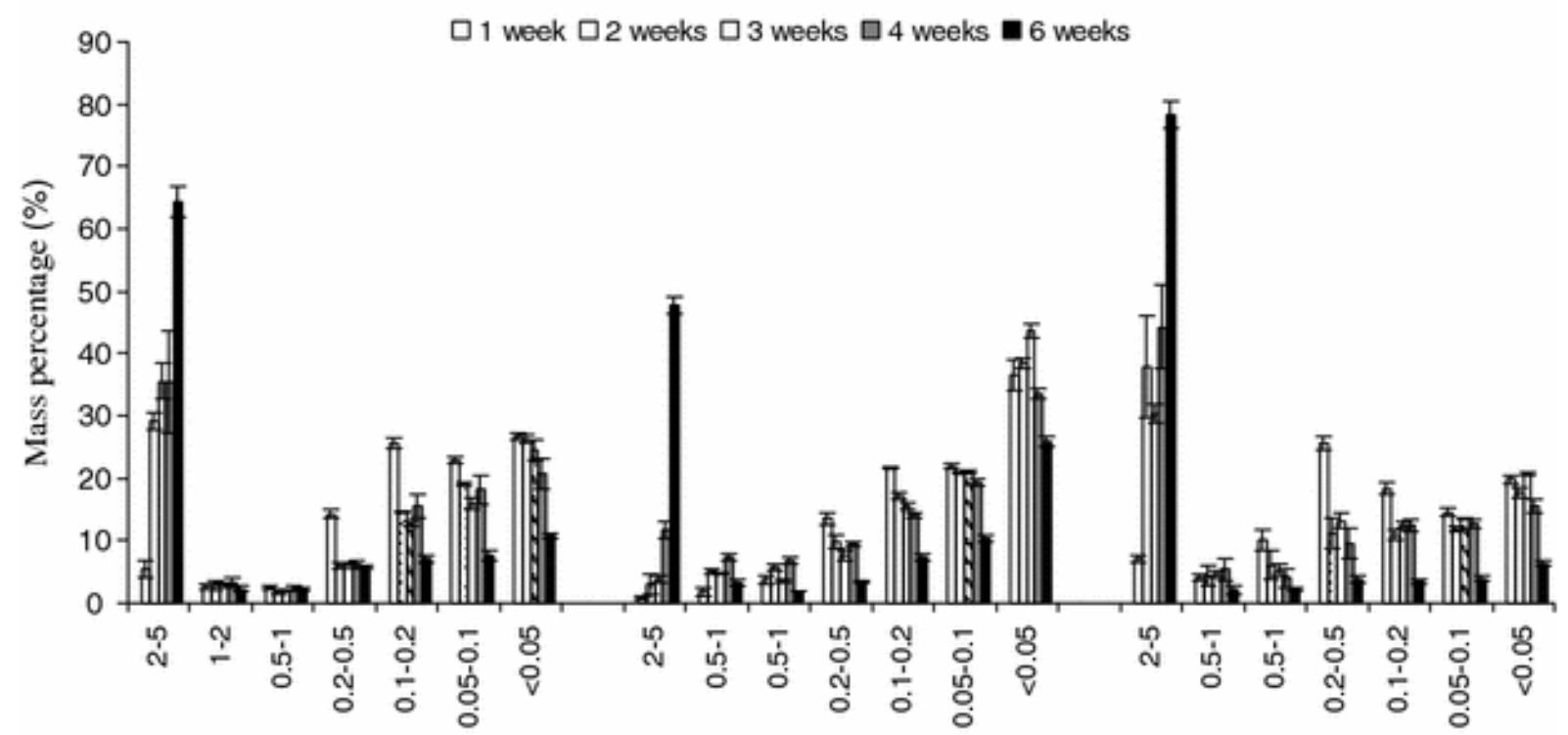

Fragment size classes (mm)

Fig. 5 Fragment size distributions of soil aggregates after the three testing treatments (Values represent mean of triplicate measurements). (A). Comparison of tests results for un-inoculated samples incubated for 1, 2, 3 and 6 weeks (B). Comparison of tests results for samples inoculated and incubated for 1, 2, 3, 4 and 6 weeks 
A Un-inoculated
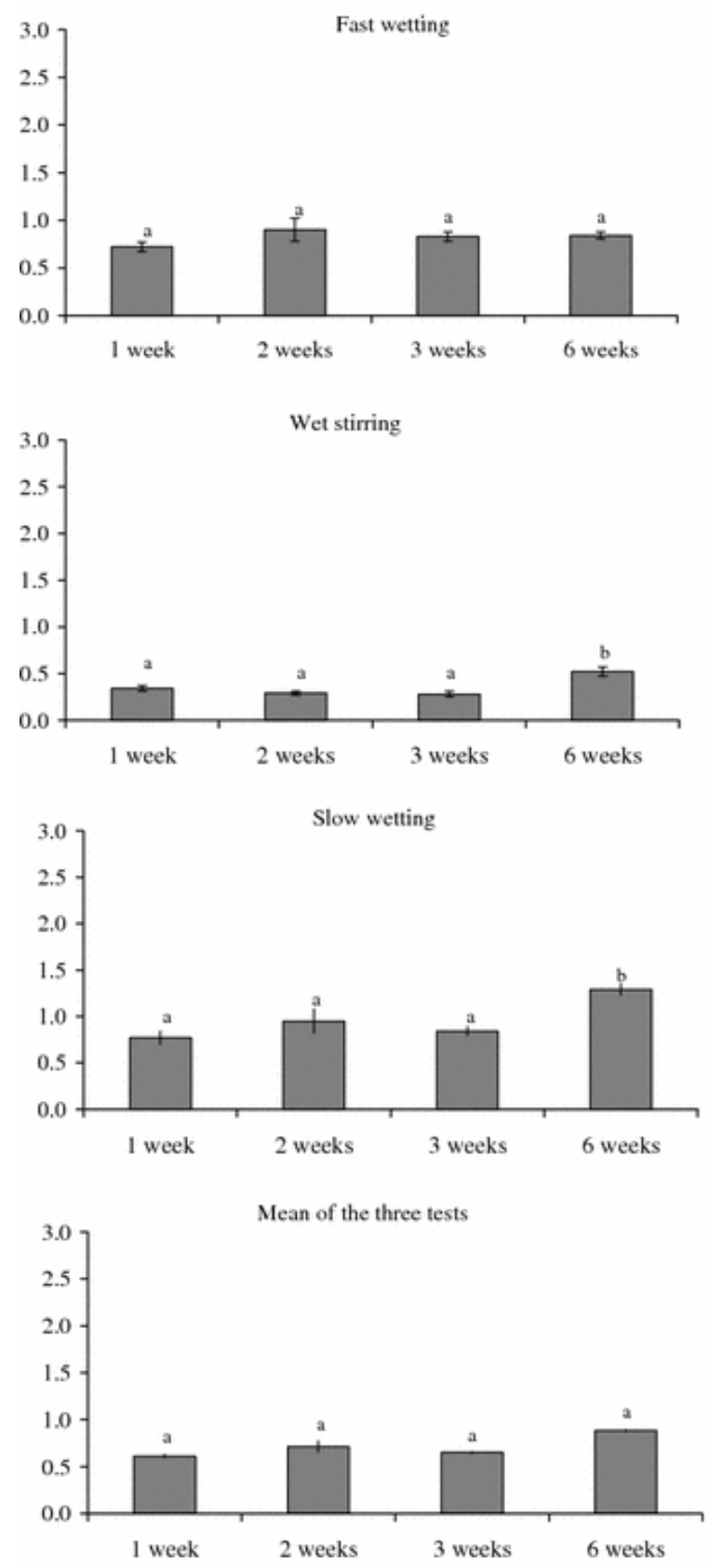

B inoculated
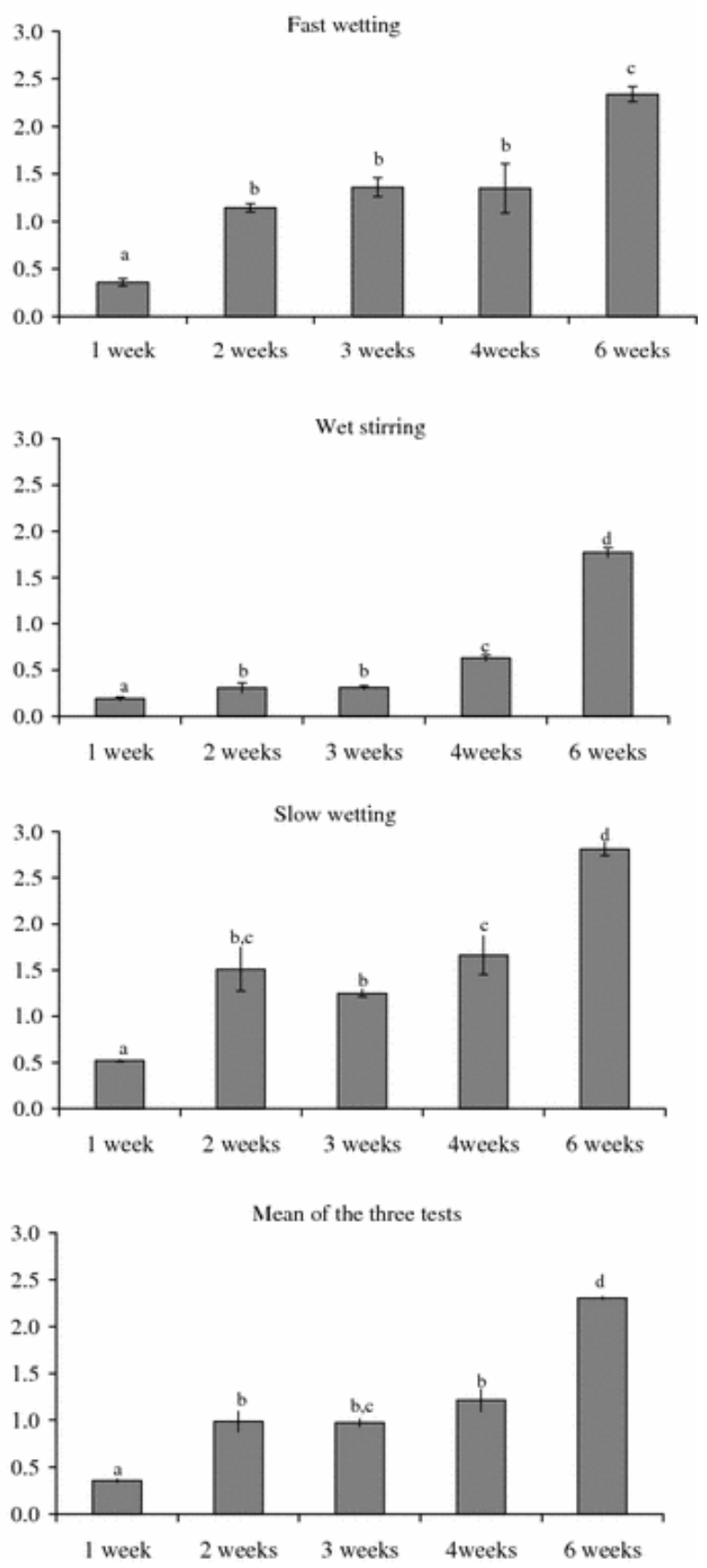

Fig. 6 Values of the Mean Weight Diameter (mean of triplicate measurements). (A) uninoculated samples incubated for 1, 2, 3 and 6 weeks. (B) Inoculated samples incubated since 1, 2, 3, 4 and 6 weeks. Values represent mean of three measurements. Values with the same letter are not significantly different, according to the multiple comparison test (95\% Tukey HSD) 


\section{Table}

Table 1 The main characteristics of the studied soil

\begin{tabular}{|l|l|l|l|l|l|l|l|}
\hline \multicolumn{2}{|l|}{ Particle-size fraction } & Aggregate stability MWD (mm) & pH & C (g/kg) & N (g/kg) & C/N \\
\hline Clay & Silt (\%) & Sand & & & & \\
\hline 13.5 & 41.0 & 45.5 & 0.56 & 5.4 & 6.1 & 0.4 & 15.3 \\
\hline
\end{tabular}

